\title{
Educação a distância na \\ Disciplina de Legislação, Ética e Exercício de Enfermagem
}

\author{
Distance education in the Discipline of Legislation, Ethics and Practice Nursing \\ Educación a distancia en la Disciplina de Legislación, Ética y Práctica de Enfermería
}

\section{Alessandra Conceição Leite Funchal Camacho' \\ 'Universidade Estácio de Sá. Faculdade de Enfermagem. Rio de Janeiro, RJ}

Submissão: $31 / 10 / 2008$

Aprovação: 15/12/2008

\section{RESUMO}

Relato de experiência cujo objetivo é descrever a inserção da disciplina de Legislação, Ética e Exercício de Enfermagem online no curso de graduação em Enfermagem da Universidade Estácio de Sá no Estado do Rio de Janeiro. A construção da interatividade na educação à distância foi fundamental para o planejamento contínuo do ambiente virtual através do desenvolvimento de habilidades e competências dos alunos exeqüíveis com a estratégia de ensino do Projeto Político Pedagógico do Curso combinando com as necessidades atuais da profissão sobre a legislação na Enfermagem. O desenvolvimento de estratégias de ensino articuladas através das ferramentas disponíveis no ambiente virtual visa promover o desenvolvimento crítico-reflexivo do futuro enfermeiro.

Descritores: Educação; Enfermagem; Educação a distância.

\section{ABSTRACT}

Report of experience whose aim is to describe the integration of the discipline of Legislation, Ethics and Practice of Nursing online in the Nursing Course at the University of Estácio Sá, Rio de Janeiro, Brazil. The construction of interactivity in distance education was critical to the continued planning of virtual environment through the development of students' feasible abilities and skills for the theching strategy of Course Political Educational Project combining with the current legislation needs of nursing profession. The development of education articulated by avaliable tools in the virtual environment aims at promoting the critical-relexive development of the future nurse.

Descriptors: Education; Nursing; Education, distance.

\section{RESUMEN}

Informe de experiencia cuyo objetivo es describir la integración de la disciplina de Legislación, Ética y Práctica de Enfermería on-line en el curso de graduación en Enfermería de la Universidad Estácio de Sa en el Estado del Río de Janeiro, Brasil. La construcción de la interactividad en la educación a distancia es fundamental para la continuación de la planificación y educación en el ambiente virtual a través del desarrollo de habilidades y competencias de los estudiantes con estrategia de enseñanza del Proyecto Político Educativo del curso en el ambiente virtual con las necesidades de la legislación actual de enfermería. El desarrollo de la educación articulada en las herramientas virtuales disponibles tiene como objetivo promover el desarrollo crítico-reflexivo de la futura enfermera.

Descriptores: Educación; Enfermería; Educación a distancia. 


\section{INTRODUÇÃO}

A educação à distância tem sido desenvolvida e utilizada em diversas áreas profissionais e acadêmicas com várias abordagens e não sendo diferente para a Enfermagem. No entanto, bem sabemos Que o desenvolvimento de pesquisas, publicações e discussões sobre o ensino on-line tem sido muito escasso.

Hoje em dia não podemos ignorar Que o uso de tecnologias em circunstâncias específicas para o ensino e educação na formação profissional de enfermeiros tem sido uma tônica atualmente. $\mathrm{O}$ Que me leva a afirmar Que este tipo de formação é particularmente relevante Quando planejado e conduzido com intervenções específicas no ambiente organizacional de trabalho visando à capacitação de profissionais baseado na dimensão da aprendizagem e a troca de conhecimentos.

Vemos instituições de ensino superior tanto no âmbito público Quanto privado desenvolvendo esforços no sentido de inserir profissionais de enfermagem capacitados no campo digital visando melhor resolução das ações interativas e articuladas seja na assistência de enfermagem através dos registros em prontuários eletrônicos, bem como, no desenvolvimento de disciplinas on-line nas estruturas curriculares e também em cursos de extensão.

No entanto, o engajamento em iniciativas de inclusão digital supõe o enfrentamento desses desafios do nosso tempo. Algo mais complexo do que meramente disponibilizar o acesso ao computador e à internet ${ }^{(I)}$.

Contudo, a internet não é mídia de massa, é uma infra-estrutura da coletividade. Os professores podem lançar mão de suas potencialidades para abrir novos espaços de participação coletiva. Eles podem experimentar isso na sala de aula presencial e on-line e aí preparar o novo espectador, a geração digital para sua atuação no novo espaço de manifestação da cidadania. Para isso, precisam atentar para interações e promover interatividade ${ }^{(1,2)}$.

De maneira mais específica é interessante focar uma área particular da educação à distância buscando a interatividade na Enfermagem como um relato de experiência relevante a ser compartilhado com meus colegas desta área. A disciplina pela Qual me refiro é Legislação, Ética e Exercício de Enfermagem desenvolvida no $4^{\circ}$ período do curso de graduação em Enfermagem da Universidade Estácio de Sá no Estado do Rio de Janeiro.

Essa nova visão de ensino on-line trouxe elementos educacionais, proporcionando uma experiência ímpar para todos os atores envolvidos (docentes e discentes) neste tipo de configuração interativa. Trata da importância da interatividade porQue hoje em dia estamos visando formar profissionais Que possam se inserir no mercado de trabalho globalizado e que sejam o diferencial para suas habilidades e competências Que serão somadas na assistência de enfermagem.

Assim, interatividade é a modalidade comunicacional Que ganha centralidade na expressão e disponibilização consciente de uma ou mais maneiras de comunicação de modo expressamente complexo presente na mensagem e previsto pelo emissor, Que abre ao receptor a possibilidades de responder ao sistema de expressão e de dialogar com ele. Representa grande salto Qualitativo em relação ao modo de comunicação de massa Que prevaleceu até o final do século XX. O modo de comunicação interativa ameaça a lógica unívoca da mídia de massa, como superação do constrangimento da recepção passiva ${ }^{(2)}$.

Portanto, o objetivo deste artigo é descrever a inserção da disciplina de Legislação, Ética e Exercício de Enfermagem on-line no curso de graduação em Enfermagem da Universidade Estácio de Sá no Estado do Rio de Janeiro.

O ensino à distância está em constante processo de transformação desde 1996, Quando foi promulgada a Lei 9394 , de 20 de dezembro daquele ano, autorizando, em seu Artigo 80, a Educação a Distância (EAD) como modo de ensino ${ }^{(3)}$. Desta forma outras regulamentações a educação à distância se estabeleceram como a Portaria 4059, de 10 de dezembro de 2004, Que autoriza a introdução de disciplinas no modo semi-presencial em até $20 \%$ da carga horária total de cursos superiores reconhecidos $^{(4)}$; a Portaria 4361 , de 29 de dezembro de $2004^{(5)}$, Que regulamenta o processo de credenciamento de instituições de ensino para o uso regular de EAD em seus processos e, finalmente, o Decreto 5622, de 19 de dezembro de 2005, Que regulamenta o Artigo 80 da Lei de Diretrizes e Bases, definindo a política oficial de educação a distância no país ${ }^{(6)}$.

A Lei de Diretrizes e Bases da Educação à Distância em consonância com as suas portarias e decreto permitem uma adesão das instituições de ensino nessa nova modalidade de ensino. É claro Que há toda uma normatização Que as instituições de ensino devem cumprir para atender a demanda não somente discente no Que tange a inclusão digital mas também as exigências exeQüíveis com a nossa realidade. É uma forma de inclusão digital permitindo o acesso ao ensino através do ambiente virtual de forma clara e fidedigna.

Acredito Que a Educação à Distância, esse novo agir na educação, pode levar os profissionais de enfermagem a desenvolver a competência continuada, através da cooperação, participação, responsabilidade, capacidade decisória e de intervenção através de seu conhecimento e reflexão da Legislação na Enfermagem. Além disso, acredito Que o desenvolvimento de sua postura crítica, reflexiva na formação discente, poderá promover, assim, a inserção necessária destes no sentido de trabalhar com interatividade, na troca de saberes.

A relevância deste artigo está no fato de compartilhar experiências sobre a educação à distância no momento em Que participei ativamente no processo de construção e elaboração da disciplina on-line de Legislação, Ética e Exercício de Enfermagem no curso de graduação em Enfermagem da Universidade Estácio de Sá desde março de 2006. O desenvolvimento desta disciplina on-line ocorreu através da construção e o planejamento prévio desta disciplina através de conteúdos próprios do exercício profissional da enfermagem. Conteúdo este de extrema relevância em termos de comunicação, informação e discussão na área da Enfermagem.

A implementação desta disciplina iniciou em agosto de 2006 com apenas uma turma on-line para fins de experiência, verificação e avaliação deste modelo de ensino no curso de Enfermagem. A turma era composta de aproximadamente 45 alunos sendo estes pertencentes aos seguintes campi da Universidade Estácio de Sá: Rebouças, Niterói, R9, Bangu, Santa Cruz, Akxe, Friburgo e Campus dos Goytacazes.

Os alunos tiveram, em seus respectivos campi aulas inaugurais com o objetivo de conhecer as ferramentas interativas do sistema, 
bem como o conteúdo programático da disciplina. Nestes encontros os alunos tiveram a oportunidade de externar suas inquietações, medos e possibilidades de troca de conhecimentos que viriam a ser desenvolvido nesta disciplina. Posteriormente, estes alunos já inclusos no ambiente virtual tiveram a possibilidade atuar ativamente nas atividades propostas da disciplina Que eram compostas por trabalhos interativos em grupo; chats previamente agendado para debates sobre o exercício profissional da enfermagem, fóruns para discussão sobre o conteúdo programático, informativos, além de trabalhos previamente programados.

Todas as atividades propostas faziam e fazem até hoje parte integrante da avaliação dos discentes desta disciplina. A partir dessa experiência vivida nestes dois anos, senti a necessidade de compartilhar sobre a Educação on-line, como estratégia para educação e inserção digital de nossos discentes visando o desenvolvimento de habilidades e competências de acordo com o Projeto Político Pedagógico de nosso curso.

\section{METODOLOGIA}

Este artigo relato de experiência sobre a implantação da disciplina on-line para de Legislação, Ética e Exercício de Enfermagem para os discentes de Enfermagem do $4^{\circ}$ período do curso de graduação em Enfermagem da Universidade Estácio de Sá.

O período de planejamento, construção e implementação desta disciplina ocorreu no ano corrente de 2006 com cursos de capacitação docente para êxito e viabilidade desta disciplina.

\section{RESULTADOS}

\section{A Construção e as Concepções Teóricas da Disciplina Online}

Tendo em vista o projeto pedagógico do Curso de Graduação em Enfermagem da Universidade Estácio de Sá no Estado do Rio de laneiro, Que prevê o desenvolvimento de um currículo integrado elaborou-se a organização e coordenação das disciplinas em eixos temáticos, entendendo eixo temático como um sistema Que utiliza áreas de interesse como diretriz para a obtenção do conhecimento científico, de maneira a buscar o entrelaçamento e o reforço das disciplinas, a fim de contribuir de modo significativo para a construção e reconstrução do conhecimento de forma Que esse conhecimento esteja a serviço de uma vida digna, autônoma e democrática, contribuindo assim para o reforço da interdisciplinaridade e da transversalidade entre as disciplinas.

A disciplina constitui-se de forma articulada ao conjunto, e representam o aporte necessário, de áreas básicas e tradicionais das ciências da vida, oferecendo também, um leque para opções de futuras especializações para o discente. Ela possibilita a oportunidade de troca de conhecimentos de legislação em enfermagem e tecnológica disponível, operacionalizam o processo educativo, privilegiando a aprendizagem vivencial, capazes de desenvolver competências cognitivas imprescindíveis ao profissional crítico, reflexivo e criativo.

Incluem-se os conteúdos referentes às diversas dimensões da relação indivíduo-sociedade contribuindo para a compreensão dos deferimentos sociais, culturais, comportamentais, psicológicos, ecológicos, éticos e legais nos níveis individual e coletivo do processo saúde-doença. Nesta disciplina são trabalhadas as Quatro linhas Gerência, Pesquisa, Saúde da Família e Ética/Bioética:

- A Pesquisa: insere-se nesta disciplina através da abordagem do Código de Ética dos Profissionais de Enfermagem e a Bioética com suas respectivas implicações e Questionamentos éticos e morais. São elementos propulsores Que possibilitam o aluno a reflexões e instigam o seu desenvolvimento na Pesquisa com repercussões para sua atuação profissional;

- A Gerência: tem como foco a aplicabilidade do Código de Ética dos Profissionais de Enfermagem e a forma como o discente (futuro profissional) apreende sua aplicação e possui noções sobre a complexidade do seu gerenciamento durante a assistência de enfermagem. Neste aspecto são discutidos estudos de caso que colocam em foco o gerenciamento das ações de enfermagem e suas implicações éticas e legais;

- Saúde da Família: engloba as Questões da Bioética aos problemas persistentes (fome, doenças, pobreza entre outros) e emergentes (globalização, clonagem, alimentos transgênicos, transplante de órgãos), cujo foco de abordagem é a forma como o profissional de enfermagem reflete sobre a repercussão Que estes temas possuem diretamente na família e sociedade e a maneira como ele deve atuar de acordo com o Código de ética dos Profissionais de Enfermagem.

- Ética e Bioética: visa a discussão da conduta do profissional de acordo com a legislação vigente na área da Enfermagem corroborada com uma postura crítica e reflexiva dos conteúdos ministrados para uma atuação profissional compatível com a realidade do respeito à vida humana.

Assim, minha atuação docente se fez presente através de algumas exigências Quanto à formação prévia do docente Que precisa dar conta de três exigências Que são: a) $O$ docente precisa transitar da mídia clássica para a mídia on-line. Para melhor entendimento, na mídia clássica a mensagem está fechada em sua estabilidade material exigindo basicamente a expressão imaginal, isto é, o movimento próprio da mente livre e conectiva Que interpreta mais ou menos livremente (jornal, fotografia, cinema, rádio e televisão), no entanto, a mídia on-line faz melhor a difusão da mensagem e vai além da mensagem pode ser manipulada, modificada à vontade podendo ser transformada dependendo da opção crítica do usuário; b) $\mathrm{O}$ docente precisa conhecer do hipertexto próprio da tecnologia digital dotado de uma estrutura dinâmica Que possibilite a interatividade através de conexões com outros sites, documentos ou no próprio documento do texto com múltiplos pontos de vistas de fácil acesso e transparência no conteúdo; c) $\mathrm{O}$ docente precisa dar conta da interatividade como possibilidade de mudança do processo clássico de comunicação, ou seja, abre ao receptor a possibilidade de estabelecer um diálogo baseado na extensa disponibilidade de informações contidas no ambiente virtual de ensino ${ }^{(2)}$.

Esta formação perpassou por toda a minha formação como docente desta disciplina e na construção interativa da mesma. Foi um processo de contínuo estudo e necessidade de aprofundamento sobre a disponibilidade das ferramentas on-line em detrimento da importância a tecnologia para a educação como nova forma de adQuirir/refletir/compartilhar conhecimentos. Na minha opinião é uma via de mão dupla onde o acesso on-line e o computador são ferramentas férteis de informação, tanto na produção de conhecimento como na sua articulação entre professor aluno. É um contínuo diálogo de saberes Que são compartilhados e 
amadurecidos.

A premissa do desenvolvimento desta disciplina foi pela possibilidade de contribuir inestimavelmente para a transformação dos métodos de ensino e da organização do trabalho nos sistemas convencionais, bem como para utilização adequada das tecnologias de mediatização da educação. É um meio muito importante e apropriado para atender a grandes contingentes de alunos de forma mais efetiva que outras modalidades, e sem riscos de reduzir a Qualidade dos serviços oferecidos em decorrência da ampliação da clientela atendida. Possibilita o acesso as tecnologias de comunicação e informação para o desenvolvimento profissional e humano, através do uso de mídias variadas, facilitando o acesso geográfico, com custo baixo. Essa modalidade de ensino facilita, portanto, a aprendizagem do profissional na própria instituição sem afastá-lo por muito tempo das suas atividades, pois poderá acontecer através de teleconferência ou videoconferência, com total interatividade, bem como, disponibilizando um arsenal de recursos multimídia.

Assim, busquei o desenvolvimento da disciplina de Legislação, Ética e Exercício de Enfermagem centrada no discente disponibilizando e incentivando os seguintes recursos:

- Disponibilidade de Links, textos e fóruns para discussão e reflexão de seus conteúdos;

- Pesquisas na Biblioteca Virtual da Saúde para discussão de textos científicos da Enfermagem sobre Ética e Exercício de Enfermagem;

- Discussão de casos clínicos com o código de ética de enfermagem nos fóruns e trabalho acadêmico;

- Os alunos apresentam seus trabalhos sobre Omissão de Socorro onde articulo seus conhecimentos com a realidade da prática profissional;

- Utilização da ferramenta de perguntas e respostas mais freqüentes onde os alunos realizam a leitura e discutem seus conflitos profissionais.

Como resultados obtidos pela implementação foi realizada uma avaliação dos 45 alunos através Comissão Própria de Avaliação durante o segundo Semestre de 2006 sobre a disciplina de Legislação, Ética e Exercício de Enfermagem onde obtivemos as seguintes informações:

- Sobre a apresentação, com clareza, pelo professor da proposta de trabalho da disciplina online (objetivos e conteúdos) foi avaliado muito bom por 54,1\% dos alunos; como bom por $29,7 \%$ dos alunos e regular por $8,1 \%$ dos alunos. Apenas $8,1 \%$ não responderam;

- Sobre o domínio do conteúdo da disciplina online pelo professor avaliado pelos alunos temos $54,1 \%$ Que consideraram como muito bom; $37,8 \%$ dos alunos consideraram como bom; $5,4 \%$ avaliaram como regular e $2,7 \%$ não responderam;

- Em relação à articulação entre teoria e prática através de exemplos concretos durante as aulas online avaliado pelos alunos temos $40,5 \%$ caracterizado como muito bom; $29,7 \%$ como bom e 24,3\% como regular. Apenas 5,4\% não responderam;

- Quanto ao incentivo docente à participação, discussão e expressão de idéias no fórum e nas comunidades virtuais vemos Que $56,8 \%$ caracterizaram como muito bom; $24,3 \%$ como bom e 13,5\% como regular. 5,4\% não responderam;

- Sobre o apoio à realização das atividades. (exercícios, tarefas, peseuisa) $54,1 \%$ dos alunos avaliaram como muito bom; $27 \%$ avaliaram como bom e 16,2\% avaliaram como regular. $2,7 \%$ não responderam;

- Em relação a coerência entre procedimentos de avaliação (provas, testes, trabalho) e o conteúdo das aulas online os alunos avaliaram Que $48,6 \%$ foi muito bom; $35,1 \%$ foi avaliado como bom e $13,5 \%$ foi avaliado como regular. 2,7\% não responderam;

- Quanto aos procedimentos para a realização de avaliações presenciais temos $43,2 \%$ dos alunos Que avaliaram como muito bom; $40,5 \%$ Que avaliaram como bom e $13,5 \%$ como regular. 2,7\% não responderam;

- Sobre os esclarecimento de dúvidas dos alunos em relação aos temas tratados temos $45,9 \%$ dos alunos Que avaliaram como muito bom; 40,5\% Que avaliaram como bom e 8, 1\% Que avaliaram como regular. Apenas 5,4\% não responderam este item;

- Sobre a rapidez das respostas aos alunos no esclarecimento de dúvidas (no fórum, nas comunidades virtuais, na central de mensagens) $54,1 \%$ dos alunos avaliaram como muito bom; $29,7 \%$ avaliaram como bom e 10,8\% avaliaram como regular. Apenas 5,4\% não responderam este item;

- Quanto ao comprometimento do professor com a modalidade de Educação a Distância (disciplinas online) temos 59,5\% Que avaliaram como muito bom; $29,7 \%$ Que avaliaram como bom e $8,1 \%$ Que avaliaram como regular. Apenas 2,7\% dos alunos não avaliaram este item.

Desta forma, a articulação do conteúdo se desenvolveu com base na visão emergente do ensino na educação à distância através da construção de temas contidos nas aulas virtuais Que são compartilhados, refletidos e discutidos entre os alunos virtuais a busca de artigos científicos virtuais centrados na sua vivência prática para discussão.

A sociedade atual requer um novo tipo de profissional em todos os setores econômicos, essa necessidade se dá pela busca de competências múltiplas das pessoas, no trabalho em equipe, na capacidade de aprender e de adaptar-se a situações novas. Para alcançarmos essas competências necessitamos de conhecimento para utilizar as novas tecnologias da informação e comunicação, não apenas como meios de melhorar a eficiência dos sistemas, mas, principalmente, como ferramentas pedagógicas efetivamente a serviço dos profissionais Que atuam na saúde ${ }^{(7)}$.

Penso Que minhas reflexões neste texto não se esgotam, porque a Inclusão Digital é um movimento de participação contínua dentro da sociedade da Informação, tendo em nossas mãos uma infinidade de soluções digitais cada vez mais surpreendentes e poderosas, principalmente para a Enfermagem. As tecnologias de comunicação e informação devem ser compartilhadas o Quanto antes, caso contrário estaremos correndo o risco de aumentarmos ainda mais os excluídos digitais. Em nossa Sociedade da Informação Que deve Que ser para todos, sua democratização deve possibilitar Que toda a população tenha acesso às novas tecnologias, utilizando-as em todo o seu potencial.

\section{CONSIDERAÇÕES FINAIS}

Reconhecer Que o mundo pós-moderno (ou contemporâneo) é obviamente diferente do mundo no Qual e para o Qual e educação (moderna) foi pensada e organizada para, a partir daí, reconhecer 
e tentar ver Que não é o mesmo Que assumir perspectivas teóricas pós-modernas para analisar as relações entre educação e mundo atual. Assim, pode-se examinar o mundo de hoje com ferramentas de ontem; mas é muito melhor tentar construir novas ferramentas para pensá-lo e examiná-lo (o mundo de hoje) a partir de novas bases Que tragam a reflexão. Essa reflexão pode permitir a construção de possibilidades educacionais Que acabam desmistificando nossas crenças anteriores e nos permitindo crescer não mais como meros espectadores mas, como àQueles Que estão no processo de construção contínua do conhecimento digital na Enfermagem.

Assim, destaco Que mesmo com as adversidades e desafios o ensino on-line é uma nova perspectiva para a área da saúde. Isso significa, de modo essencial, substituir uma proposta da educação tradicional por uma nova proposta, na Qual os docentes ensinam e os alunos aprendem mediante situações não-convencionais, ou seja, em espaços e tempos Que não compartilham. Para tanto, utiliza-se de uma multiplicidade de recursos pedagógicos com o objetivo de facilitar a construção do conhecimento ${ }^{(7)}$.

Consideramos área de Educação em Enfermagem pode ser subdividida em dois subgrupos: 1) educação para a formação ou atualização profissional e 2) educação do paciente ou cliente. Existem inúmeras formas de utilização dos recursos do sistema Internet na área de educação/ensino de enfermagem. Porém, tais recursos ainda não são explorados uniformemente em nível mundial. Em países desenvolvidos, onde a estrutura universitária considera e aproveita o sistema Internet, existe maior utilização e conseQüente benefício para esta área. Já nos países subdesenvolvidos e/ou em desenvolvimento, a utilização dos recursos varia de acordo com a tecnologia disponível de país a país e com as iniciativas locais da própria enfermagem, as Quais refletem o desenvolvimento de pesquisas na área de Informática em Enfermagem ${ }^{(8)}$.

Concordo Que a preparação pedagógica para os enfermeiros, o Que com certeza constitui estratégia para atenuar as dificuldades, precisa investir na preparação do enfermeiro, motivando-os ao envolvimento com a função de ensinar de forma mais estimulante e responsável. Acreditam ser estratégias adequadas para verificar o alcance de um curso Formação Pedagógica em Educação Profissional na Área da Saúde, no caso a Enfermagem, Que se utiliza da recente e inovadora tecnologia de ensino, denominada "educação à distância"(9).

Portanto, destaco como contribuição relevante deste artigo a possibilidade de buscar a interatividade na educação on-line nos seguintes aspectos Que foram determinantes na construção da disciplina de Legislação, Ética e Exercício de Enfermagem: a) planejar continuamente o ambiente de educação on-line; b) desenvolver as habilidades e competências da disciplina exeeüíveis com a estratégia de ensino do Projeto Político Pedagógico do Curso; c) o docente ser um instrumento de incentivo contínuo ao discente; d) combinar o ambiente virtual com as necessidades atuais da profissão no Que tange as constantes modificações da legislação da Enfermagem.

Para finalizar, trago duas recomendações relevantes diante dessa minha experiência: a primeira está centrada no estabelecimento do desenvolvimento de estratégias de ensino articuladas com o conteúdo programático da disciplina através das ferramentas disponíveis no ambiente virtual. Segundo, visando desenvolvimento crítico e reflexivo do futuro profissional enfermeiro em Que o ensino deve sempre ser centrado no aluno. É uma atividade de incentivo contínuo ao estudante de enfermagem considerando suas perspectivas no sentido de desenvolver sua capacidade de decisão nas atividades propostas.

\section{REFERÊNCIAS}

1. Silva M. Inclusão digital é participação e colaboração na era digital e não meramente 0 acesso às tecnologias digitais. Barcelona: Gedisa; 2005.

2. Silva M. Internet na educação e inclusão social na era digital, na sociedade da informação e na cibercultura. Rio de laneiro: EDUERJ; 2008.

3. Ministério da Educação e Cultura (BR). Lei 9.394 de 20 de Dezembro de 1996. Brasília: Ministério da Educação e Cultura; 1996.

4. Ministério da Educação e Cultura (BR). Portaria 4059, de 10 de Dezembro de 2004. Brasília: Ministério da Educação e Cultura; 2004.

5. Ministério da Educação e Cultura (BR). Portaria 4361, de 29 de Dezembro de 2004. Brasília: Ministério da Educação e Cultura; 2004.

6. Ministério da Educação e Cultura (BR). Decreto 5622, de 19 de Dezembro de 2005. Brasília: Ministério da Educação e Cultura; 2005.

7. Oliveira M A N. Educação à distância como estratégia para a educação permanente em saúde: possibilidades e desafios. Rev Bras Enferm 2007; 60(5): 585-9.

8. Santos SGF, Marques IR. Uso dos recursos de Internet na Enfermagem: uma revisão. Rev Bras Enferm 2006; 59(2): 212-6.

9. Silva VR, Silva MG, Santos LBO. Proposta pedagógica do PROFAE na perspectiva dos enfermeiros instrutores. Rev Bras Enferm 2005; 58(3):284-9. 